\title{
Six-Year-Old Child Model in Frontal Sled Test
}

\author{
H. Čechová * \& L. Hynčík \\ Research Centre New Technologies, University of West Bohemia, Pilsen, Czech Republic, \\ *Corresponding author: hcechov@ntc.zcu.cz
}

\begin{abstract}
This paper deals with a demonstration of a six-year-old child model. The model, called Bobby, belongs to a family of human rigid body models, Robby, and was created within the computational environment of the PAM system. First of all, Bobby is updated, the geometry and material properties of the original model are improved, and, in particular, joints, including their characteristics, are redefined. The updated model is tested in a sled test environment. Due to lack of experimental data with child cadavers, the test is compared to an experiment with the six-year-old Anthropomorphic Test Device, published in available literature sources.
\end{abstract}

KEY WORDS: biomechanics, virtual human model, six year old child, sled test, injury criteria.

\section{INTRODUCTION}

That the safety of child car passengers is still a current topic is demonstrated by the following facts. According to the European Child Safety Alliance, road traffic injuries are the leading cause of death and severe injuries among children aged $0-14$ years, and are the cause of $34 \%$ of child injuries and deaths annually. New rules and standards concerning children's seats and restraint systems are continually updated. Most of the research uses dummy models (Malott et al. 2004; Palisson et al. 2007; Paine, 2001). However, human models are becoming more precise and more biofidelic (Haug et al. 2004; Ć́halová, 2009) with the ability to understand human body behavior, and are able to describe injury analysis in more detail. The research community also tends towards the legalization of human body models in the car industry (Haug et al. 2003).

The paper deals with a six-year-old child model and its validation in a sled test environment. The model used, called Bobby, belongs to a Robby family of human articulated rigid body based models created within the long term cooperation with the ESI Group company (Haug et al. 2004). The Robby family furthermore includes a 50\% male Robby and a 5\% female Robina. A simple scaling tool for the creation of age dependent models was developed as well (Hynčík et. al. 2007). The original 50\% male model Robby was successfully validated with experimental sled tests with human cadavers (Hynčík, 2001). Moreover, the Robby13, a scaled male body to that of a 13-year-old boy, was compared to the experiments carried out with the 13-year-old cadaver of a boy at the University of Heidelberg (Hynčík et al. 2007).

The aim of the study is to complete the Robby family with a tuned child model for impact purposes, and introduce a sled test. Since no experimental data of a six-year-old (6YO) boy are available, the Bobby sled test simulation is compared to the results presented 
in Malott et al. (2004) where the sled test with a six-year-old Anthropomorphic Test Device (ATD) is performed.

\section{METHODS}

\subsection{Six-year-old child model}

Bobby represents a six-year-old child who weighs $24 \mathrm{~kg}$ and is $1.13 \mathrm{~m}$ tall. The current model is based on the original version presented by Morille, (2001). From an anatomical point of view the model is represented by a skeleton covered by skin which serves for contact surfaces determination and also for the aesthetic aspect. From the mechanical point of view the body is created by 23 rigid bodies connected by 26 kinematic joints.

The rigid bodies represent particular body segments. The segment generally includes bearing bones and a particular part of skin. It is also characterized by its center of gravity (COG), mass and inertia properties taken from Morille, (2001).

Compared to the original version of Bobby, all joint elements and characteristics are defined according to Robbins, (1983) where the joint limits for an average adult male are published, since no similar child data are available. Except the spine, wrists and knees, all the joints in the body are of a spherical type. The wrist is compounded of two joints. The radius-hand joint is spherical and the ulna-hand joint enables translation in the vertical direction and rotation around the mediolateral axis. The knee joint of the spherical type is extended with one translational degree of freedom in the vertical direction. The spine is divided into four parts connected by flexion-torsion joints. The joints are between the first neck vertebrae ( $\mathrm{C} 1$ called atlas) and the head (clivus), between the seventh neck vertebra (C7) and the first thoracic vertebra (T1), the third one is between the twelfth thoracic (T12) and first lumbar (L1) and last one connects the fifth lumbar (L5) and sacrum.

The remaining joints in the spine are of the flexion-torsion type. The shoulder girdle is created by two spherical joints between the clavicle and sternum and clavicle and scapula. Scapula slides over the rib-cage creating a so called physiological joint. The mutual joint orientation is given by local coordinate frames depicted in Figure 1, left. Penetrations during possible movement of particular body parts are prevented by sliding contacts.

\subsection{Sled test environment}

The simulation of a frontal sled test with a six-year-old child model is performed. The originally standing model is positioned into the sled. The sitting Bobby model can be found in Figure 1.
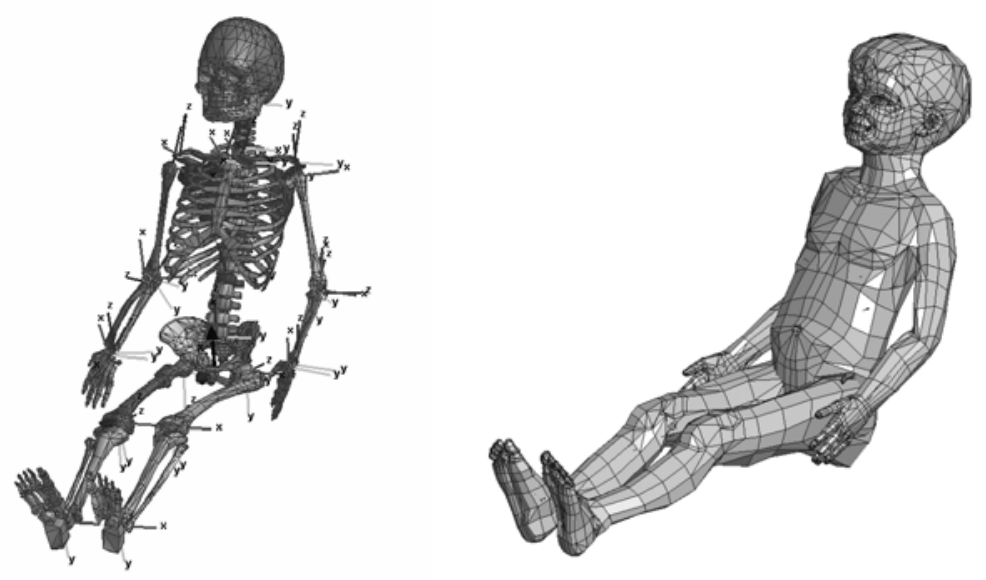

Figure 1: Bobby sitting in the car position. 
The sled is carried out with a three point belt and a standard seat equipped with a child pillow (booster seat). The belt is without a force limiter and modeled as a fast belt system (PAM, 2006). The whole seat including the booster is modeled as rigid. The behavior of rigid bodies during the impact is refined by a soft contact involving stiffness of enclosed parts (PAM, 2006).

The arms, the feet and the back part of the head of the child model are preserved from penetrations with the seat by sliding interfaces. The generic $30 \mathrm{mph}$ (corresponding to $48 \mathrm{~km} / \mathrm{h}$ approximately) with $125 \mathrm{~ms}$ duration American Automobile Manufacturers Association (AAMA) pulse is used, see Figure 2. The pulse acceleration is prescribed by the following expression:

$$
a(t)=-168.73 \sin \left(\frac{\pi \cdot t}{0.125}\right)
$$

The child model is accommodated by accelerometers giving the local accelerations in the head, spine and pelvis.
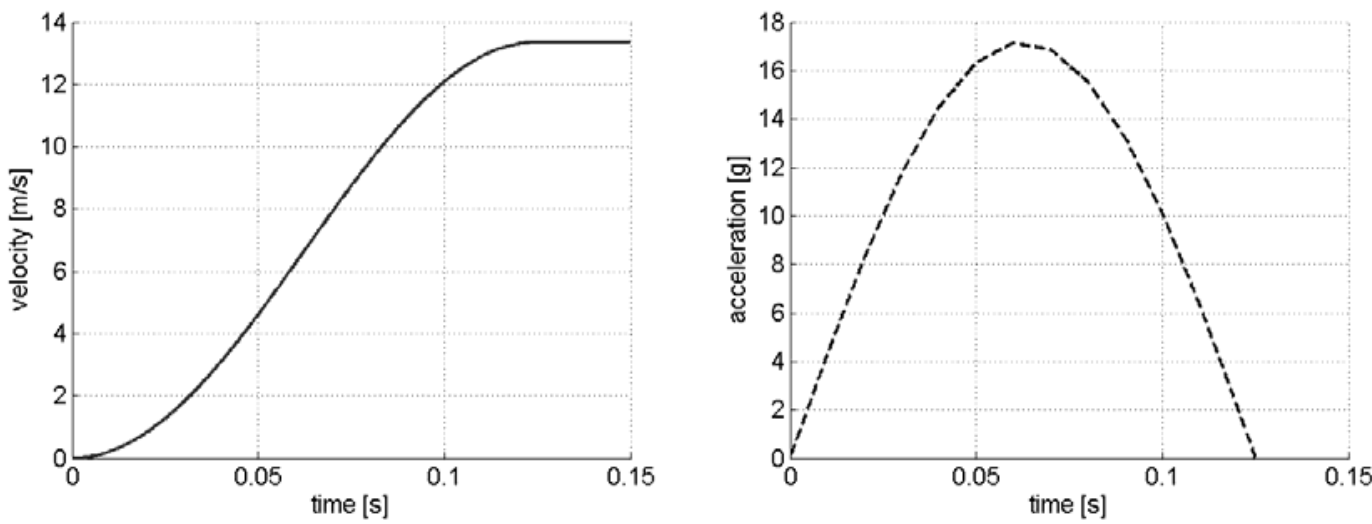

Figure 2: Time-velocity and time-acceleration dependencies of AAMA sled pulse.

\subsection{Injury criteria}

The severity of an injury is described through the so called injury scales. The most widely used injury scale is the Abbreviated Injury Scale (AIS) which was first developed in 1971 and it is still being updated; see Eppinger et al. (1999). Using rigid body models we are not able to directly recognize accident consequences on a human body. The measure of injury is determined by different injury criteria based on body parts acceleration or on tension force and bending moment which are summarized in Schmitt, (2004).

Table 1: Summary of injury measures.

\begin{tabular}{|l|r|}
\hline Injury measure & IARV \\
\hline Neck $-\mathrm{N}_{\mathrm{ij}}$ & 1 \\
Chest $-3 \mathrm{~ms}$ & 60 \\
$\mathrm{Head}-\mathrm{HIC}_{15}$ & 723 \\
\hline
\end{tabular}

The standard $\mathrm{HIC}_{15}$ criterion is used to treat the head injury, the $\mathrm{N}_{\mathrm{ij}}$ criterion for the neck and finally the $3 \mathrm{~ms}$ criterion for the thorax is applied. The particular Injury Assessment Reference Values (IARVs) for six-year-old ATD are summarized in Table 1. The used IARVs represent a $25 \%$ chance of an AIS $\geq 3$ injury, and they are specified by NHTSA in Eppinger 
et al. (1999) except the $\mathrm{HIC}_{15}$ which is taken from Mertz et al. (1997). Table 2 states the critical intercept values limiting the "safety" area (marked by the solid line in Figure 7) used for $\mathrm{N}_{\mathrm{ij}}$ determination.

Table 2: Limits for neck injury criteria for the 6 year old dummy (PAM, 2006).

\begin{tabular}{|l|r|}
\hline Load & Critical intercept values \\
\hline Tension $[\mathrm{N}]$ & 2800 \\
Compression $[\mathrm{N}]$ & 2800 \\
Flexion $[\mathrm{Nm}]$ & 93 \\
Extension $[\mathrm{Nm}]$ & 37 \\
\hline
\end{tabular}

\section{RESULTS AND DISCUSSION}

Since no experimental data for a six-year-old (6YO) boy are available, the Bobby sled test simulation is compared to results presented by Malott et al. (2004) where the frontal sled test with a six years old ATD is performed.

\subsection{Sled test kinematics}

The overview on the body behavior of the $6 \mathrm{YO}$ child model during the sled test can be described as follows. During the first $60 \mathrm{~ms}$ the body moves forward due to inertia forces. Then the body is restrained by the belt system, and the flexion of its upper part occurs. After $140 \mathrm{~ms}$ the body starts to move back. The upper and lower extremities are pushed up. The kinematics are documented in Figure 3 at different times. The comparison with the 6YO ATD with the backless booster variant (Malott et al. 2004) is shown in Figure 4.

The model's kinematics are monitored and accelerations are measured in the head and in the first thorax vertebra and in the sacrum of the child model. These dependencies are used to compute injury measures analyzed in the following paragraph. They are shown in Figure 5. The curves are filtered by Sae180 filter to emphasize important peaks. All the curves follow a similar trend.

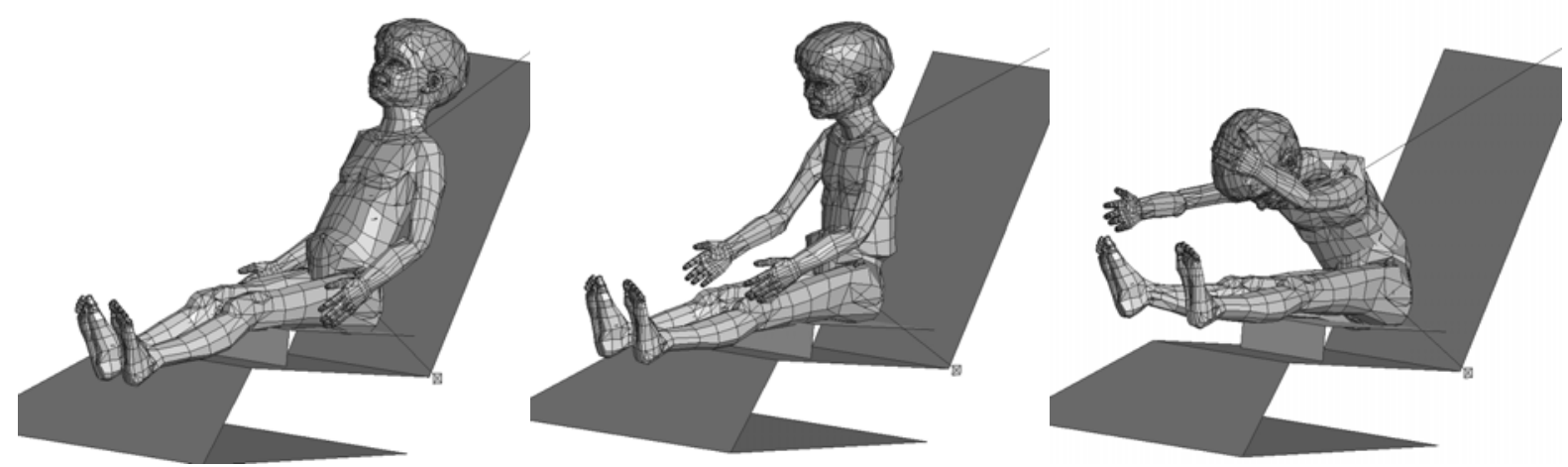

Figure 3: Sled test kinematics at 40, 80 and $120 \mathrm{~ms}$.

The experimental belt peak forces occur between $2000 \mathrm{~N}$ and $3500 \mathrm{~N}$ in the case of the lap belt and between $2000 \mathrm{~N}$ and $7500 \mathrm{~N}$ in the case of the shoulder belt for various 
experimental settings. The back less booster variant which corresponds to the presented simulation is assessed in Table 3.

Since detailed belt characteristics are not specified in Mallot et.al. (2004), the standard fast belt system is used. The belt system generates the greatest force between 60 and $130 \mathrm{~ms}$. The lap belt peak force corresponds to the experimental one, while the shoulder experimental one is greater as summarized in Table 3 .
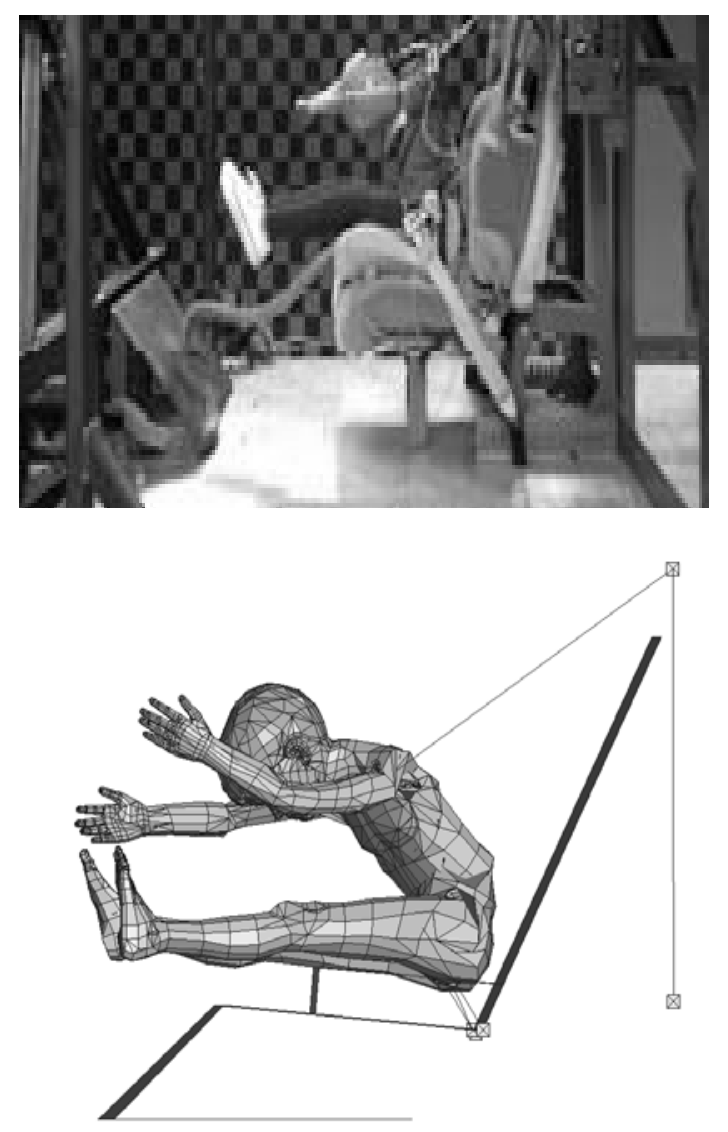

Figure 4: Experimental ATD's (Malott et al. (2004)) and Bobby's kinematics at $120 \mathrm{~ms}$.

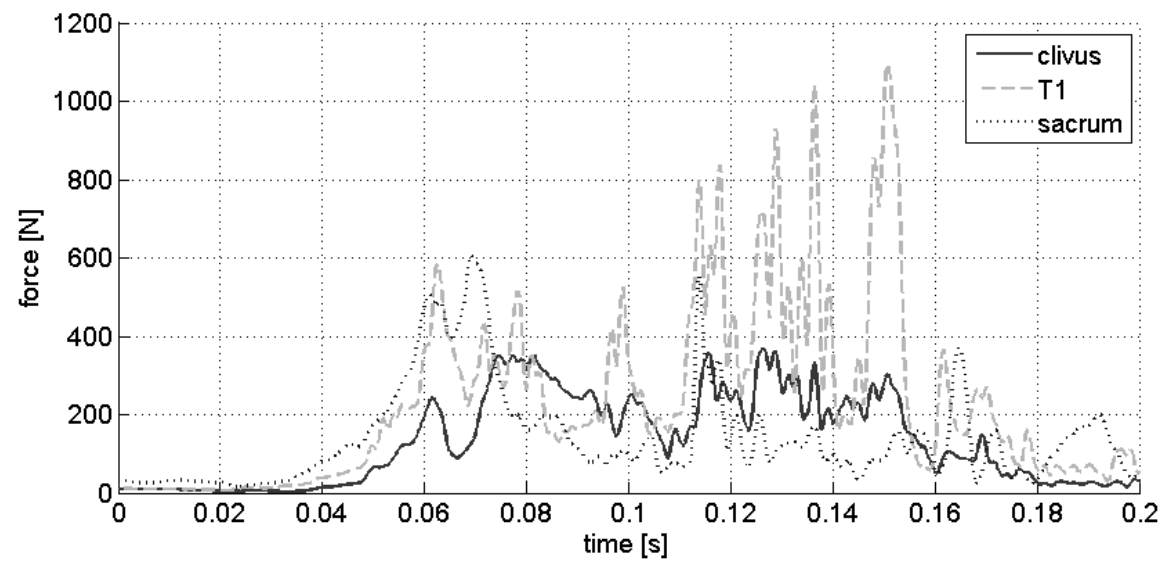

Figure 5: Acceleration magnitude of the head (Clivus), the first thorax vertebra (T1) and the sacrum. 


\subsection{Injury analysis}

The results are computed from filtered acceleration curves, where the filters are chosen according to recommendations published in PAM, (2006).

The graph in Figure 7 shows the neck tension (measured in the first cervical vertebra). It would be critical if the points exceed the marked region. The kite shape determines the injury limit corridor for the 6YO child, see Schmitt (2004). The flexion moment at the horizontal axis goes from extension (negative part) to flexion (positive part), and the vertical axis expresses the axial force from compression (negative part) to tension (positive part). Circles note the forces in the $\mathrm{C} 1$-head joint in time.

During the first $60 \mathrm{~ms}$ the head is subjected to compression with soft flexion and then soft extension. Between 60 and $110 \mathrm{~ms}$ the tension and soft flexion occurs, between 110 and $140 \mathrm{~ms}$ tension and extension, and after $140 \mathrm{~ms}$ the circles oscillates around the origin. The greatest loading can be observed when the greatest belt force is generated.

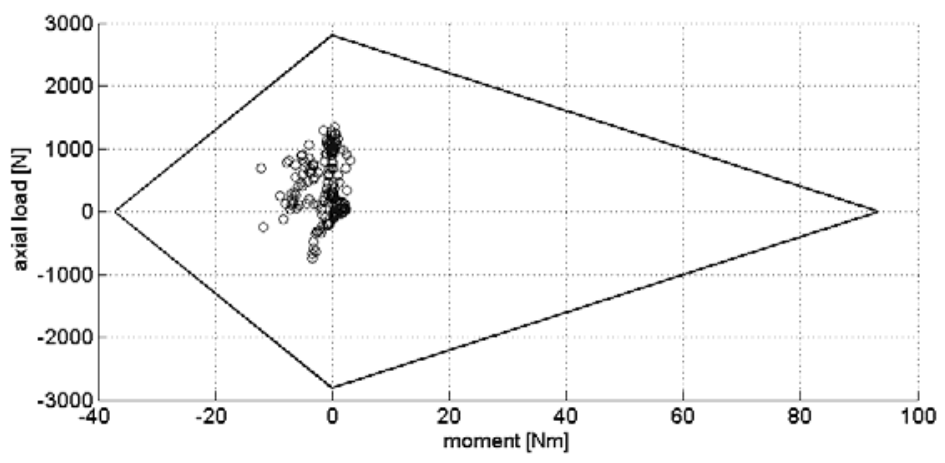

Figure 7: Axial load and bending moment dependency measured in the occipital condyle during the sled test.

The Bobby's injury analysis is compared to experimental results obtained with 6YO ATD. The simulation results are slightly lower than the experiment's, as can be seen in Table 3. The injury measures are normalized by the particular IARV. Concerning $\mathrm{HIC}_{15}$ and $3 \mathrm{~ms}$, both the values are well under the injury limit so the differences are not crucial in this case.

Table 3: Comparison of 6YO ATD's and Bobby's characteristics.

\begin{tabular}{|l|c|c|}
\hline & 6YO ATD & Bobby \\
\hline Shoulder belt peak force [N] & 7100 & 2800 \\
Lap belt peak force [N] & 2100 & 2400 \\
Chest acceleration (3ms) normalized by IARV & 0.61 & 0.57 \\
HIC $_{15}$ normalized by IARV & 0.28 & 0.12 \\
$\mathrm{~N}_{\mathrm{ij}}$ & 0.98 & 0.79 \\
\hline
\end{tabular}

\section{CONCLUSION}

The demonstration with a rigid body based model of a six-year-old boy was presented. The model completes the Robby family of articulated human models designed for crash test 
purposes. Firstly, the model was updated; principally, the rigid bodies and joints structures and joint characteristics were corrected.

Bobby's behavior in the frontal sled test was successfully compared to experimental results performed with the 6YO ATD. The results were analyzed by virtue of injury criteria. The standard head $\left(\mathrm{HIC}_{15}\right)$, neck $\left(\mathrm{N}_{\mathrm{ij}}\right)$ and thorax $(3 \mathrm{~ms})$ criteria were applied.

\section{ACKNOWLEDGEMENT}

The work is supported by the project CG911-044-150 of the Czech Ministry of Transport and by the John H. and Amy Bowles Lawrence Foundation. Great thanks belong to the ESI Group International.

\section{REFERENCES}

Č́ihalová, L., 2009: Analysis of thoracic impact responses and injury prediction by using FE thoracic model. Engineering Mechanics, Engineering Academy of the Czech Republic, Vol. 16, No. 1, pp. 49-64.

European Child Safety Alliance, EuroSafe: Child Road Safety Fact Sheet.

http://www.dsi.univ-paris5.fr/AcVC/Publications/EuroSafe\%20Child\%20Road\%20Safety\%20Fact\%20Sheet.pdf

Eppinger R. et al. 1999: Development of improved injury criteria for the assessment of advanced automotive restraint systems - II. NHTSA, 1999. (http://ntl.bts.gov/lib/11000/11600/11669/rev_criteria.pdf)

Haug, E., Beaugonin, M., Montmayeur, N., Marca, C., Choi, H., 2003: Toward legal virtual crash tests for vehicle occupant safety design using human models. ESI Software S:A., France.

Haug, E., Choi, H.Y., Robin, S., Beaugonin, M., 2004: Human models for Crash and impact simulation. Special volume of Handbook of numerical analysis, vol. XII, (Editor P.G. Ciarlet) Elsevier, North Holland, pp. 231-670.

Hynčík, L., 2001: Rigid body based human model for crash test purposes. Engineering Mechanics, Enginering Academy of the Czech Republic, Vol. 8, No. 5, pp. 1-6.

Hynčík, L., Nováček, V., Bláha, P., Chvojka, O., Krejčí, P., 2007: On scaling of human body models. Applied and computational mechanics, University of West Bohemia, Pilsen, Vol. 1, No.1, pp. 63-74.

Malott, A., Parenteau, C., Arbogast, K., Mari-Gowda, S., 2004: Sled Test Results Using Hybrid III 6 Year Old: An Evaluation of Various Restrains and Crash Configurations. SAE Technical paper series 2004-01-0316.

Mertz, H. J., Prasad, P., Irwin, A. L., 1997: Injury risk curves for children and adults in frontal and rear collisions (SAE 973318). Proceedings of the $41^{\text {st }}$ Stapp Car Crash Conference (P-315), pp. 13-30, Society of Automotive Engineers.

Morille, N., 2001: Modélisation Enfant Biofidele 6 ans. Rapport de stage, ESI Group. 
Schmitt, K. U., Niederer, P., Walz, F., 2004: Trauma Biomechanics, Introduction to Accidental Injury. Springer-Verlag, Germany.

Palisson, A., Cassan, F., Trosseille, X., Lesire, P., Alonzo, F., 2007: Estimating Q3 dummy injury criteria for frontal impacts using the child project results and scaling reference values. Proceedings of IRCOBI Conference, Maastricht 2007.

Paine, M., Brown, J, 2001: Crash and sled tests using child dummies. http://members.optusnet.com.au/mpaineau/paine_brown_crdata.pdf

PAM-System Manuals, Version 2006

Robbins, D.H., 1983: Anthropometric Specifications for Mid-Sized Male Dummy, Volume 2. University of Michigan Transportation Research Institute (UMTRI), research report number UMTRI-83-53-2. 